\title{
Gastrointestinal bleeding after cardiac surgery: Does describing the disease prescribe the cure?
}

\author{
Verdi J. DiSesa, MD, MBA
}

\footnotetext{
From the Division of Cardiac Surgery, Department of Surgery, Lewis Katz School of Medicine at Temple University, Philadelphia, Pa.

Disclosures: Author has nothing to disclose with regard to commercial support.

Received for publication Feb 7, 2017; accepted for publication Feb 10, 2017; available ahead of print March 8, 2017.

Address for reprints: Verdi J. DiSesa, MD, MBA, Division of Cardiac Surgery, Department of Surgery, Lewis Katz School of Medicine at Temple University, Philadelphia, PA 19140 (E-mail: Verdi.disesa@ gmail.com). J Thorac Cardiovasc Surg 2017;154:189 $0022-5223 / \$ 36.00$

Copyright (C) 2017 by The American Association for Thoracic Surgery http://dx.doi.org/10.1016/j.jtcvs.2017.02.019
}

This article reports an analysis of the incidence of, risk factors for, and pathology associated with gastrointestinal (GI) bleeding requiring endoscopy in 9017 patients undergoing cardiac surgical procedures (mainly coronary artery bypass grafting) at a single hospital over a 10-year period. ${ }^{1}$ Ninety-one ( $1 \%$ ) patients suffered a GI bleed deemed severe enough to require endoscopic evaluation. Risk factors included age, reduced ejection fraction, congestive heart failure, valve surgery, cerebrovascular disease, renal disease, GI disease, and the preoperative prescription of warfarin (Coumadin). Duodenal ulcer was the predominant pathological lesion $(78 \%)$ and stress gastritis accounted for $8 \%$ of bleeding episodes. GI bleeding was evaluated if it occurred between 0 and 30 days of operation. The median number of postoperative days on which bleeding occurred was 10 . Mortality of patients who had GI bleeding was $8.8 \%$, significantly higher than the $4.3 \%$ mortality observed in patients without GI bleeding. Finally, bleeding episodes were more common during the second postoperative week. The authors suggest that preoperative evaluation and treatment for peptic ulcer disease might ameliorate the incidence and consequences of bleeding after cardiac surgery.

At one level, this study confirms the intuitive notion that sicker patients with the risk factors enumerated are more likely to suffer other complications like GI bleeding. However, this study's findings are likely to be of interest to surgeons and other clinicians taking care of patients, who are older and sicker these days, after heart operations. The authors' findings have implications for perioperative therapy and management and therefore may lead to improvements in patient care and outcomes.

The authors acknowledge that the exclusion of patients who had GI bleeding but did not undergo endoscopy is a

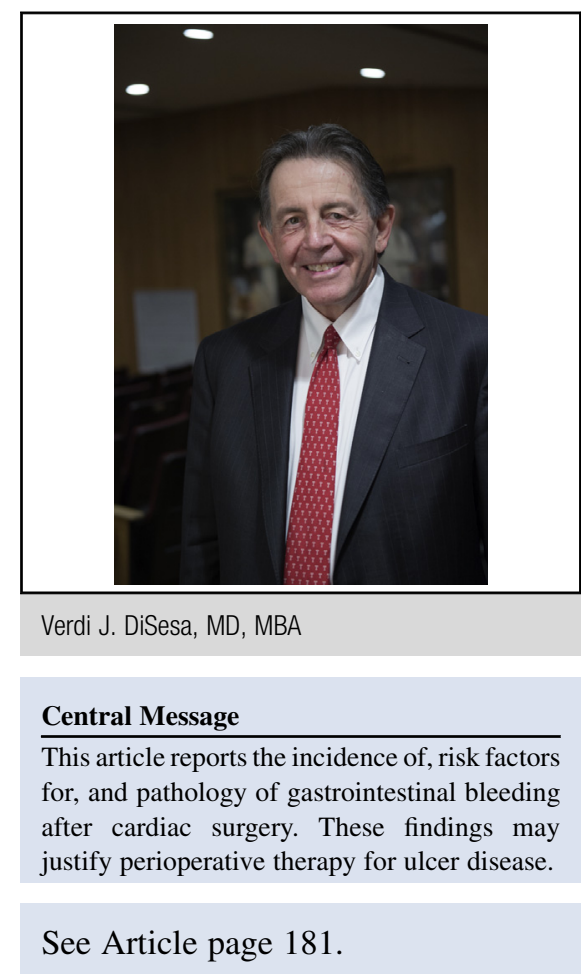

potential confounder. Other questions to which the clinician might want answers include the following:

- What are the clinical characteristics of those patients whose GI bleeding stopped with medical management without an endoscopic diagnosis?

- Should clinical practice be modified based on these findings?

- Specifically, should patients with significant risk factors for GI bleeding be treated expectantly for latent duodenal peptic ulcer disease before, during, or after cardiac surgery?

\section{Reference}

1. Krawiec F, Maitland A, Duan Q, Faris P, Belletrutti PJ, Kent WDT. Duodenal ulcers are a major cause of gastrointestinal bleeding after cardiac surgery. J Thorac Cardiovasc Surg. 2017;154:181-8. 